\title{
Penerapan Hazard Analysis And Critical Control Point Di Main Kitchen Hotel Ibis Styles Yogyakarta
}

\author{
Tri Widianto $^{1}$, Citra Unik Mayasari ${ }^{2}$ \\ Akademi Pariwisata BSI Yogyakarta \\ Email : citra.cyu@bsi.ac.id
}

\begin{abstract}
Food safety is very important to avoid the occurrence of side effects caused by contamination, abuse and food poisoning. There are several things that cause the decline of food quality, such as the lack of proper food storage, processing and presentation that is not in accordance with the applicable procedures. Cases that often occur in hotels are food that is in the buffet becomes damaged or quickly stale after several hours served and raw or undercooked food ingredients do not last long in storage. Hence the need for a system that regulates ways to deal with these problems. One such system is Hazard Analysis and Critical Control Point (HACCP). HACCP aims to identify and control hazards from the reception of materials, storage, production processes to the presentation of guests. Researchers want to know how far HACCP is applied in main kitchen hotel lbis Styles Yogyakarta. In this study the authors use descriptive qualitative methods, with data collection techniques in the form of direct observation, interviews with staff purchasing and main kitchen, documentation and literature study. The result of this research is the application of HACCP essential for the storage and presentation of food at Hotel Ibis Styles Yogyakarta. It aims to maintain the quality of food or food at Hotel Ibis Styles Yogyakarta.
\end{abstract}

Keywords: Food And Beverage Product Department, Hazard Analysis And Critical Control Point (HCCP), Main Kitchen.

Abstrak: Keamanan pangan merupakan hal yang sangat penting untuk menghindari terjadinya efek samping yang ditimbulkan dari kontaminasi, penyalahgunaan dan keracunan pada makanan. Ada beberapa hal yang menyebabkan menurunnya kualitas pangan, diantaranya adalah penyimpanan bahan makanan yang kurang tepat, pengolahan dan penyajian yang tidak sesuai dengan prosedurprosedur yang berlaku. Kasus-kasus yang sering terjadi di hotel adalah makanan yang berada di buffet menjadi rusak atau cepat basi setelah beberapa jam disajikan dan bahan makanan mentah maupun setengah matang tidak bertahan lama di dalam penyimpanan. Maka dari itu perlu adanya sistem yang mengatur cara-cara menangani masalah-masalah tersebut. Salah satu sistem tersebut adalah Hazard Analysis and Critical Control Point (HACCP). HACCP bertujuan untuk mengidentifikasi dan pengendalian bahaya (hazard) mulai dari penerimaan bahan, penyimpanan, proses produksi hingga penyajian kepada tamu. Peneliti ingin mengetahui sejauh mana HACCP diterapkan di main kitchen hotel Ibis Styles Yogyakarta. Dalam penelitian ini penulis menggunakan metode deskriptif kualitatif, dengan teknik pengambilan data berupa observasi secara langsung, wawancara dengan staff purchasing dan main kitchen, dokumentasi dan studi pustaka. Hasil dari penelitian ini adalah penerapan HACCP penting bagi penyimpanan dan penyajian pada makanan di Hotel lbis Styles Yogyakarta. Hal ini bertujuan untuk menjaga kualitas bahan makanan atau makanan di Hotel Ibis Styles Yogyakarta.

Kata Kunci: Food And Beverage Product Department, Hazard Analysis And Critical Control Point (HCCP), Main Kitchen.

\subsection{Latar Belakang}

Perkembangan dunia pariwisata yang begitu cepat akan sangat mempengaruhi perekonomian masyarakat, dan juga akan mempengaruhi usaha-usaha di sektor pariwisata seperti pelayanan akomodasi restoran, tempat wisata keluarga, tempat wisata budaya dan mempengaruhi usaha perhotelan tentunya. Hotel merupakan akomodasi yang sangat penting bagi dunia pariwisata dikarenakan pada era modern ini perjalanan wisata yang jauh sudah sangat mungkin untuk di lakukan, maka dari itu wisatawan sangatlah membutuhkan jasa penginapan seperti hotel. Maraknya usaha hotel membuat para pengusaha bersaing untuk memberikan pelayanan yang maksimal bagi para wisatawan. Pelayanan yang memuaskan sangatlah penting untuk memberikan kesan yang baik bagi para tamu atau wisatawan supaya mereka memiliki keinginan untuk menginap kembali ke hotel tersebut. Pelayanan seperti kenyamanan, keramahan sampai pada kualitas produk sangatlah berpengaruh terhadap kepuasan tamu.

Food and beverage product department adalah departemen yang bertanggung jawab 
ataskualitas pelayanan di bidang produk makanan. Seperti di Hotel lbis Styles Yogyakarta, food and beverage product department sangat memperhatikan kualitas dan keamanan produk atau makanan yang akan disajikan kepada tamu. Kualitas dan keamanan suatu produk makanan tidak terlepas dari prosedur-prosedur dan aturanaturan pengolahan makanan, aturan dan prosedur tersebut diterapkan dalam suatu sistem yang di sebut Hazard Analysis and Critical Control Point (HACCP). HACCP bertujuan untuk mengidentifikasi dan pengendalian bahaya (hazard) mulai dari penerimaan bahan, penyimpanan, proses produksi hingga penyajian kepada tamu. Kebersihan dan keamanan pangan akan berpengaruh terhadap kepuasan pelanggan yang akan memberi dampak positif bagi Hotel lbis Styles Yogyakarta, dan akan meminimalisir timbulnya complaint untuk departemen tersebut khususnya dan untuk hotel pada umumnya.

Keamanan pangan merupakan hal yang sangat penting untuk menghindari terjadinya efek samping yang ditimbulkan dari kontaminasi, penyalahgunaan dan keracunan pada makanan. Ada beberapa hal yang menyebabkan menurunnya kualitas pangan, diantaranya adalah penyimpanan bahan makanan yang kurang tepat, pengolahan dan penyajian yang tidak sesuai dengan prosedurprosedur yang berlaku. Kasus-kasus yang sering terjadi di hotel adalah makanan yang berada di buffet menjadi rusak atau cepat basi setelah beberapa jam disajikan dan bahan makanan mentah maupun setengah matang tidak bertahan lama di dalam penyimpanan. Maka dari itu perlu adanya sistem yang mengatur cara-cara menangani masalahmasalah tersebut.

\subsection{Perumusan Masalah}

Dari uraian latar belakang di atas, maka penulis dapat dirumuskan masalah dalam penelitian ini, sebagai berikut:

1. Bagaimana penerapan Hazard Analysis and Critical Control Point (HACCP) dalam penyimpanan bahan baku di main kitchen Hotel lbis Styles Yogyakarta?

2. Bagaimana penerapan Hazard Analysis and Critical Control Point (HACCP) dalam penyajian di Hotel Ibis Styles Yogyakarta?

3. Apa saja permasalahan di mainkitchen Hotel Ibis Styles Yogyakarta?

4. Bagaimana upaya Hotel lbis Styles Yogyakarta dalam menangani permasalahan di mainkitchen?

\subsection{Landasan Teori}

\subsubsection{Pengertian Hotel}

Sulastiyono (2011), hotel adalah suatu perusahaan yang menyediakan pelayanan makanan, minuman dan fasilitas kamar untuk tidur kepada orang-orang yang melakukan perjalanan dan mampu membayar dengan jumlah yang wajar sesuai dengan pelayanan yang diterima tanpa adanya perjanjian khusus. UU No.10 Tahun 2009 Tentang Kepariwisataan, "hotel merupakan salah satu dari usaha penyedia akomodasi yang memberikan layanan penginapan dalam tata kelola pariwisata selain vila, pondok wiasata, bumi perkemahan, persinggahan karavan dan lain sebagainya".

\subsubsection{Pengertian Kitchen}

Pengertian kitchen menurut Sihite dalam Widyastuti (2012) adalah sebuah ruangan di mana di dalamnya terdapat beberapa fasilitas perlengkapan untuk memasak.

1. Fungsi Utama Kitchen

Fungsi utama kitchen atau dapur menurut Sihite dalam Widyastuti(2012) adalah:

a. Pusat kegiatan proses bahan baku makanan di hotel.

b. Pusat kegiatan pengolahan makanan di hotel.

c. Pusat kegiatan masak-memasak makanan di hotel.

d. Tempat menghasilkan resep yang baku suatu hidangan di hotel.

e. Alat pengukur reputasi dan image hotel, melalui pengolahan makanan.

\subsection{Hazard Analysis and Critical Control Point (HACCP)}

Menurut Sugiono (2013) "HACCP merupakan peranti atau sarana untuk melakukan penilaian terhadap suatu bahaya kemudian menetapkan sistem pengendalian bahaya tersebut yang memfokuskan pada pencegahan bahaya yang teridentifikasi tersebut, dan bukan mengandalkan sebagian besar pada pengujian produk akhir". Dalam Sugiono (2013) HACCP terdiri dari tujuh prinsip, yaitu:

1. Pelaksanaan analisis bahaya

2. Penentuan titik kendali kritis

3. Penetapan batas kritis

4. Penetapan sistem pemantauan terhadap titik kendali kritis

5. Penetapan tindakan perbaikan yang dilakukan ketika hasil pemantauan menunjukan bahwa suatu titik kendali kritis tersebut tidak dalam keadaan terkendali

6. Penetapan prosedur verifikasi untuk memastikan bahwa sistem HACCP berjalan secara efektif 
7. Penetapan dokumentasi mengenai semua prosedur dan rekaman yang sesuai dengan prinsip-prinsip penerapannya

Sugiono (2013) juga mengatakan bahwa

HACCP memiliki pedoman umum untuk menerapkan sistem tersebut yang terdiri atas 12 langkah, yaitu:

1. Pembentukan tim HACCP

2. Deskripsi produk

3. Identifikasi maksud penggunaan (dalam hal ini makanan yang di santap)

4. Penyusun bagan alir

5. Kepastian di tempat kerja terhadap bagan alir tersebut

6. Pendaftaran semua bahaya potensial yang berkaitan dengan tahapan, analisis bahaya dan saran berbagai tindakan untuk mengendalikan bahaya-bahaya yang teridentifikasi (perwujudan dari Prinsip 1)

7. Penentuan titik kendali kritis (perwujudan dari Prinsip 2)

8. Penetuan batas-batas kritis pada tiap titik kendali kritis (perwujudan dari Prinsip 3)

9. Penyusunan sistem pemantauan untuk tiap titik kendali kritis (perwujudan dari Prinsip 4)

10. Penetuan tindakan perbaikan (perwujudan dari Prinsip 5)

11. Penetuan prosedur verifikasi (perwujudan dari Prinsip 6)

12. Penetuan dokumen dan perekaman (perwujudan dari Prinsip 7)

\subsection{Penyimpanan Bahan Makanan}

Penyimpanan bahan makanan merupakan satu dari 6 prinsip higiene dan sanitasi makanan. Penyimpanan bahan makanan yang tidak baik, terutama dalam jumlah yang banyak (untuk katering dan jasa boga) dapat menyebabkan kerusakan bahan makanan tersebut. Adapun tata cara penyimpanan bahan makanan yang baik menurut sitem HACCP dalam Anonim (2010) adalah sebagai berikut:

1. Suhu penyimpanan yang baik

2. Tata cara menyimpan

\subsection{Penyajian Makanan}

Penyajian makanan merupakan salah satu prinsip dari hygiene dan sanitasi makanan. Penyajian makanan yang tidak baik dan etis, bukan saja dapat mengurangi selera makan sesorang tetapi dapat juga menjadi penyebab kontaminasi terhadap bakteri. Beberapa hal yang harus diperhatikan dalam penyajian makanan sesuai dengan prinsip hygiene dan sanitasi makanan dalam Yuda (2009) adalah sebagai berikut:
1. Prinsip wadah artinya setiap jenis makanan ditempatkan dalam wadah terpisah dan diusahakan tertutup.

2. Prinsip kadar air artinya penempatan makanan yang mengandung kadar air tinggi (kuah, susu) baru dicampur pada saat menjelang dihidangkan untuk mencegah makanan cepat rusak.

3. Prinsip edible part artinya setiap bahan yang disajikan dalam penyajian adalah merupakan bahan makanan yang dapat dimakan.

4. Prinsip pemisahan artinya makanan yang tidak ditempatkan dalam wadah seperti makanan dalam kotak (dus) atau rentang harus dipisahkan setiap jenis makanan agar tidak saling bercampur.

5. Prinsip panas yaitu setiap penyajian yang disajikan panas, diusahakan tetap dalam keadaan panas seperti soup, gulai dan lain-lain.

6. Prinsip alat bersih artinya setiap peralatan yang digunakan seperti wadah dan tutupnya, dus, piring, gelas, mangkuk, harus bersih dan dalam kondisi baik.

\subsection{Kontaminasi Silang}

Menurut Sugiono (2013) kontaminasi silang adalah "keadaan dimana bakteri tersebar di anatara makanan, permukaan, atau peralatan". Hal ini paling mungkin terjadi saat menyentuh pangan mentah kemudian menyentuh atau menetes pada makanan siapsaji, peralatan, permukaan, atau perpindahan bakteri berbahaya dari pangan terkontaminasi ke pangan tidak terkontaminasi, baik melalui persentuhan langsung maupun tidak langsung. Kontaminasi silang ini merupakan salah satu penyebab keracunan makanan yang paling umum. Oleh sebab itu, Sugiono (2013) menulis hal-hal yang harus dilakukan untuk menghindarinya:

1. Bersihkan permukaan tempat-kerja, alas pemotong (cuting board), perabot dan peralatan lain secara seksama sebelum menyiapkan makanan dan setelah menggunakannya untuk menyiapkan makanan mentah.

2. Idealnya, gunakan alas pemotong dan pisau yang berlainan (warna atau bentuknya) untuk pangan mentah dan matang atau siap-santap.

3. Cuci tangan sebelum menyiapkan pangan.

4. Cuci tangan dengan seksama setelah menyentuh pangan mentah.

5. Simpanlah pangan mentah dan siap-saji secara terpisah kapan saja, selamanya.

6. Simpan pangan mentah di bawah pangan siap-saji dalam lemari pendingin yang sama, jika jumlah lemari pendinginnya 
terbatas. Jika mungkin, gunakan lemari pendingin yang berlainan untuk pangan mentah dan masak /siap-santap.

7. Yakinkan bahwa staf mengetahui bagaimana mencegah kontaminasi silang.

\subsection{Metode Penelitian}

Metode yang digunakan adalah menggunakan metode deskriptif kualitatif. Sugiyono (2009) menyatakan metode deskriptif adalah "metode yang digunakan untuk menggambarkan atau menganalisis suatu hasil penelitian tetapi tidak digunakan untuk membuat kesimpulan yang lebih luas". Dalam penelitian ini peneliti melakukan observasi langsung dan wawancara dengan staff purchasing dan main kitchen.

\subsection{Tehnik Pengumpulan Data}

Tehnik pengumpulan informasi berupa data-data yang dibutuhkan untuk menganalisis objek penelitian ini adalah :

1. Observasi

Mahadewi dan Utama (2012) observasi adalah "cara pengumpulan data yang dilakukan dengan cara mengamati dan mencatat secara sistematik gejala-gejala yang diselidiki". Penulis mengamati secara langsung segala kegiatan yang berkaitan dengan Hazard Analysis and Critical Control Point (HACCP) di hotel lbis Styles Yogyakarta, dari dampak terkecil sampai dampak yanglebih besar.

2. Wawancara (Interview)

Mahadewi dan Utama (2012) wawancara adalah "proses tanya-jawab dalam penelitian yang berlangsung secara lisan". Penulis melakukan wawancara tanya jawab langsung kepada juru masak atau chef dan staf main kitchen di Hotel lbis Styles Yogyakarta.

3. Dokumentasi (Documentation)

Mahadewi dan Utama (2012) dokumentasi adalah "pengambilan data yang diperoleh melalui dokumen-dokumen". Penulis mendokumentasikan hal-hal yang dianggap perlu dan dapat menjadi bukti penelitian. Seperti foto keadaan chiller, table preaparation, tabel pengecekekan suhu pada chiller.

4. Studi Pustaka (Literature)

Nazir (2011) Studi pustaka selain dari mencari sumber data sekunder yang akan mendukung peenelitian, juga diperlukan untuk mengetahui sampai kemana ilmu yang berhubungan dengan penelitian telah berkembang. Penulis mengambil data melalui buku yang berkaitan dengan bidang yang diteliti salah satunya adalah buku tentang HazardAnalysis and Critical Control Point (HACCP).

\subsection{Pembahasan}

4.1.1. Penerapan Hazard Analysis and Critical Control Point (HACCP) dalam penyimpanan bahan baku di main kitchen Hotel Ibis Styles Yogyakarta

Penyimpanan pada umumnya adalah suatu kegiatan yang dilakukan atau diterapkan dalam segala kegiatan yang berhubungan dengan barang seperti bahan baku makanan atau barang-barang lain. Dalam hal ini ada beberapa peraturan yang mengatur tata cara menyimpan bahan makanan dengan baik, penyimpanan dengan prosedur yang sesuai akan berdampak pada kualitas makanan. Seperti di main kitchen Hotel Ibis Styles Yogyakarta, pengawasan terhadap penyimpanan sangatlah penting dikarenakan makanan atau bahan makanan akan sangat rentan atau mudah rusak jika cara penyimpanan tidak tepat. Berikut ini adalah prosedur-prosedur penyimpanan di main kitchen Hotel Ibis Styles Yogyakarta:

1. Penerimaan barang dari Purchasing

Semua bahan baku makanan yang di butuhkan oleh hotel, khususnya oleh main kitchen akan melalui bagian purchasing terlebih dahulu. Purchasing akan mengecek bahan baku makanan yang sudah di pesan dari supplier sesuai dengan standar perusahaan atau tidak, apabila bahan makanan atau barang yang di pesan tidak sesuai dengan yang di pesan atau tidak sesuai dengan standar perusahaan bagian purchasing akan mengembalikan atau menolak barang tersebut kepada supplier. Jika sudah memenuhi standar persyaratan, pihak purchasing akan menginformasikan kepada bagian main kitchen jika bahan makanan yang di pesan sudah datang sesuai dengan yang di butuhkan. Pihak main kitchen akan mengambil bahan makanan yang sudah di pesan dan harus menyimpan bahan tersebut dengan baik dan benar agar bahan makanan tersebut tidak mudah rusak. Sebelum di simpan bahan makanan seperti sayuran dan buah harus di bersihkan terlebih dahulu dan di pisahkan sesuai dengan jenisnya. Setelah di bersihkan dan di pisahkan sesuai jenisnya baru di masukkan ke dalam almari pendingin atau chiller. Bahan makanan seperti daging, ikan, unggas dan seafood juga di pisahkan sesuai dengan jenisnya, kemudian di masukkan ke dalam box penyimpanan yang bersih. Setelah di masukkan ke dalam box yang bersih tulis 
tanggal penyimpanan di luar box agar semua karyawan mengetahui bahan makanan mana yang harus di gunakan terlebih dahulu untuk menghindari kerusakan bahan makanan karena terlalu lama dalam penyimpanan.

2. Suhu penyimpanan

Setiap bahan baku makanan memiliki spesifikasi penyimpanan yang berbeda, tergantung dari jenis, jumlah, ukuran dan tempat penyimpanannya. Beberapa bahan baku makanan dapat di kelompokkan menjadi:

a. Bahan baku makanan jenis daging, unggas ikan atau seafood

Bahan makanan ini termasuk dalam penyimpanan bahan makanan cold food, biasa di simpan dalam suhu di bawah $40^{\circ} \mathrm{F}$. Bahan makanan yang di simpan dengan suhu di bawah $40^{\circ} \mathrm{F}$ masa penyimpanan bertahan selama 7 hari sejak penyimpanan. Dalam almari penyimpanan atau chiller terdapat temperature control dimana setiap pergantian shift staff kitchen harus mengkontrol suhu temperature penyimpanan tersebut. Karena apabila suhu melebihi batas minimal penyimpanan bahan makanan akan terkontaminasi oleh bakteri-bakteri yang bisa menyebabkan kerusakan bahan makanan.

b. Bahan baku sayuran dan buahbuahan

Dalam penyimpanan sayur dan buah harus di pisahkan untuk mencegah proses pembusukan. Bahan baku sayuran dan buah-buahan juga di pisahkan sesuai dengan jenisnya. Bahan baku seperti brokoli, apel, wortel, tomat, kol dan sejenisnya memerlukan suhu penyimpanan sekitar $40-50{ }^{0} \mathrm{~F}$. Bahan kering seperti bawang merah dan bawang putih memerlukan suhu penyimpanan sekitar $32-39^{\circ}$ F. Rata - rata penyimpanan bahan makanan ini adalah 1 minggu.

c. Bahan makanan jenis telur dan susu Penyimpanan bahan makanan untuk satu minggu suhu penyimpanan harus di bawah $-5^{\circ} \mathrm{C}$ toleransi maksimal suhu $8^{\circ} \mathrm{C}$

d. Bahan makanan kering seperti tepung, biji-bijian di simpan di dalam dry store dengan suhu ruangan rata-rata $25^{\circ} \mathrm{C}$.

3. Penyimpanan bahan makanan kering

a. Dry store harus benar dalam keadaan kering b. Dry store harus memiliki penerangan yang cukup

c. Dry store harus memiliki ventilasi udara yang cukup

d. Rak penyimpanan harus mudah di jangkau

e. Penempatan dan pengambilan barang diatur dengan sistem FIFO (First InFirst Out)

f. Membuat check list daftar stock barang agar memudahkan dalam pengecekan persediaan barang.

4.1.2. Penerapan Hazard Analysis And Critical Control Point (HACCP) Dalam Penyajian Di Hotel Ibis Styles Yogyakarta.

Penyajian makanan adalah tahap akhir dari semua proses di kitchen, di sinilah makanan akan di taruh diatas alat saji dan disajikan kepada tamu. Dalam penyajian makanan perlu diperhatikan hal-hal penting, seperti mengenai keamanan tempat penyajian, kebersihan dan kelayakannya berikut adalah aspek-aspek yang diperhatikan dalam penyajian di Hotel lbis Styles Yogyakarta:

1. Kebersihan Alat Saji

Hal yang paling penting dalam penyajian adalah kebersihan alat saji, hal ini dikarenakan makanan akan berinteraksi langsung dengan alat penyajian. Untuk menjaga kebersihan alat saji perlu diperhatikan dalam penyimpanan alat saji.

2. Penyimpanan alat saji

Alat yang saji harus disimpan di tempat yang kering dang tidak lembab, hal ini untuk mencegah timbulnya jamur dan parasit lain yang dapat menyebabkan kontaminasi terhadap makanan yang akan disajikan. Biasanya untuk penyimpanan alat saji untuk hot food alat sajinya pun disimpan di tempat yang memiliki temperatur yang hangat.

3. Kelayakan alat saji

Alat saji yang digunakan untuk menyajikan makanan haruslah layak, maksudnya adalah sebuah alat saji seperti, mangkuk, piring dan sendok tidak boleh memiliki kecacatan dalam bentuk fisiknya. Karena hal ini dapat mengurangi estetika dari makanan itu sendiri dan mengurangi penampilan dari makanan tersebut.

Jenis-jenis alat penyajian pun berbedabeda mengikuti dari style penyajian, setiap penyajian memiliki cara yang berbeda pula. Seperti yang diterapkan oleh Hotel Ibis Style Yogyakarta meliputi:

1. Penyajian dalam bentuk buffet

Buffet atau biasa kita sebut dengan prasmanan adalah cara penyajian dimanamakanan yang disajikan berada di 
tempat yang memuat cukup banyak makanan dan para tamu akan mengambil makanan sendiri. Dalam penyajian ini biasanya menggunakan Serving Dish yaitu alat saji yang memiliki pemanas dibawahnya guna menjaga agar makanan tetap panas. Hal ini bertujuan untuk menghindari danger zone atau zona bahaya pada makanan, zona bahaya pada makanan yaitu dimana makanan berada di luar tempat penyimpanan dalam waktu lebih dari 4 jam dan dalam suhu ruangan $6-65^{\circ}$ C. Jika makanan lebih dari 4 jam dalam temperatur ruangan seperti yang disebutkan maka makanan tersebut bisa terindikasi adanya pertumbuhan bakteri.

2. Penyajian dalam bentuk Ala Carte

Ala Carte adalah suatu susunan menu, diamana makanan yang dicantumkanpada daftar makanan tersebut disertai dengan harga tersendiri. Biasanya tamu akan memesan terlebih dahulu kepada pelayan atau pramusaji, lalu oleh pramusaji akan diinformasikan kepada bagian dapur dalam bentuk captain order, setelah itu baru akan dibuatkan makanan sesuai dengan pesanan tamu. Hal ini lebih terjamin kualitas makanannya dikarenakan makanan yang disajikan masih dalam keadaan panas, dalam artian makanan yang masih baru. Alat penyajian yang digunakan pun menyesuaikan dengan pesanan, misalnya makanan yang dipesan adalah Sechuan prawn maka alat penyajinya adalah dinner plate

3. Penyajian dalam bentuk Room Service atau layanan kamar

Layanan kamar atau Room Service hampir sama dengan Ala Carte, hanya saja langkah-langkah penyajiannya berbeda. Jika Ala Carte biasanya tamu memesan di restoran hotel akan tetapi room service dipesan dari kamar hotel. Yang menjadi pembeda adalah proses pelayanannya dikarenakan makanan yang akan disajikan haruslah dibawa kekamar yang pada dasarnya jarak kamar dari kitchen lumayan memakan waktu. Oleh karena itu jika ada layanan kamar maka haruslah makanan dingin dulu yang dibuat setelah itu baru makanan panas. Alat penyajiannya hampir sama hanya saja ditambahkan food cover guna menghindari kontak langsung dari udara terbuka.

\subsubsection{Permasalahan di Main Kitchen Hotel Ibis Styles Yogyakarta}

Dalam melaksanakan kegiatan-kegiatan di kitchen lbis Styles Yogyakarta, banyak mengalami permasalahan. Permasalahanpermasalahan tersebut adalah sebagai berikut:
1. Jika hotel sedang banyak event barang yang dibutuhkan akan sangat banyak, di sini keteresediaan tempat penyimpanan biasanya menjadi masalah.

2. Kelalaian yang sering terjadi dalam penyimpanan atau FIFO yang tidak dijalankan sesuai dengan prosedur, hal ini juga menjadi masalah, misalnya saat menyimpan bahan makanan. Bahan makanan yang terlebih dahulu datang atau bahan makanan yang lama tidak boleh berada di bawah seharusnya berada di atas atau di depan bahan makanan baru. Hal ini mencegah terjadinya bahan makanan kadaluwarsa atau busuk karena penyimpanan yang terlalu lama.

3. Kurangnya pengendalian bahaya pangan yang sesuai dengan $H A C C P$, sehingga sering terjadi kontaminasi terhadap bahan makanan lain. Sebagai contoh bahan makanan yang tidak memiliki daya simpan yang lama adalah sayur, jika saat penyimpanan ada sayur yang busuk harus segera dipisahkan dengan sayur yang masih segar untuk menghindari penularan pembusukan pada sayuran.

4. Dalam hal penyajian Breakfast Hotel lbis Styles Yogyakarta menggunakan buffet pada StreetRestaurant mereka, kendala disini adalah biasanya servingdish yang digunakan akan menurun temperaturnya pada jam-jam tertentu hal ini akan membuat makanan menjadi bau dan berkurang kualitasnya.

4.1.4. Upaya Mengatasi Permasalahan di MainKitchen Hotel Ibis Styles Yogyakarta

Untuk mengatasi permasalahan yang ada, Hotel lbis Styles melakukan upaya upaya untuk mengatasi permasalahan tersebut, bentuk upaya yang dilakukan yaitu:

1. Jika barang yang datang banyak, maka cara mengatasinya adalah dengan cara mengeluarkan barang yang lama dari penyimpanan dan mengusahakan untuk memakai barang lama tersebut untuk segala bentuk kegiatan memasak di mainkitchen Hotel Ibis Styles Yogyakarta.

2. Untuk mengatasi masalah kelalaian dalam menjalankan prosedur, maka yang dilakukan adalah menekankan akan bahaya pada kelalaian dalam penyimpanaan yang tidak sesuai prosedur.

3. Untuk mengatasi ini traning HACCP akan diberikan kepada setiap karyawan atau staf yang dirasa kurang paham tentang pentingnya pengendalian bahaya yang sesuai dengan prinsip $H A C C P$.

4. Permasalahan yang sebenarnya sering terjadi dikebanyakan hotel pada umumnya 
yaitu penurunan kualitas makanan pada Breakfast, Lunch maupun Dinner Buffet, hal ini dapat diatasi dengan cara selalu mengecek pemanas pada serving dish dan mengganti makanan yang sudah mulai menunjukan tanda-tanda penurunan kualitas dengan makanan yang baru.

\subsection{Kesimpulan}

Berdasarkan hasil penelitian yang telah diuraikan pada bab sebelumnya dapat ditarik beberapa kesimpulan sebagai berikut:

1. Hotel Ibis Styles Yogyakarta memiliki prosedur penyimpanan yang sesuai dengan sistem Hazard Analysis and Critical Control Point (HACCP), yang diantaranya:

a. Proses penerimaan bahan makanan di main kitchen yang akan disimpan.

b. Pengaturan suhu penyimpanan.

c. Cara-cara penyimpanan yang sesuai sistem Hazard Analysis and CriticalControl Point (HACCP).

d. Penempatan dan pengambilan barang sesuai sistem FIFO (First In First Out).

e. Penggunaan tempat penyimpanan yang cukup memadai seperti thawing chiller, meat and fish freezer, vegetable chiller, dry store dan hot box.

2. Penyajian makanan makanan yang memperhatikan segala aspek sesuai dengan Hazard Analysis and Critical Control Point (HACCP), seperti memperhatikankebersihan alat saji, penyimpanan alat saji dan kelayakan alat saji. Membedakan jenis-jenis penyajian supaya dapat menyesuaikan masakan dengan sifat-sifat penyajian tersebut juga diperhatikan oleh Hotel lbis Styles Yogyakarta.

3. Dalam melaksanakan kegiatan-kegiatan di main kitchen Ibis Styles Yogyakarta, banyak mengalami permasalahan, seperti:

a. Ketersediaan tempat penyimpanan bahan makanan.

b. Kelalaian terhadap system penyimpanan FIFO.

c. Kurangnya pengendalian bahaya pangan sesuai $H C C P$.

d. Penurunan suhu pada penyajian makanan dan kontaminasi silang.

4. Untuk mengatasi permasalahan yang ada, Hotel Ibis Styles melakukan upaya-upaya untuk mengatasi permasalahan tersebut, upaya yang dilakukan diantaranya:

a. Penggunaan barang yang lama terlebih dahulu FIFO

b. Menekankan akan bahaya pada kelalaian dalam penyimpanaan yang tidak sesuai prosedur.

c. Pemberian training tentang Hazard Analysis and Critical Control Point (HACCP) kepada setiap karyawan main kitchen.

d. Pengecekan secara berkala kepada setiap makanan yang menunjukan penurunan kualitas makanan.

\section{Daftar Pustaka}

[1] Anonim. 2010. Penyimpanan Bahan makanan Merupakan Satu dari enam Prinsip Higiene dan Sanitasi makanan. Retrived March 11, 2018, from http://himateta.Ik.ipb.ac.id/2010/12/penyim panan-bahan-makanan-merupakan-satudari-6-prinsip-higiene-dan-sanitasimakanan-by-anonim-tep45/. 5 Januari 2018

[2] Mahadewi, E. Ni Made dan Rai Utama, I.G. Bagus. 2012. Metode Penelitian Pariwiasata dan Perhotelan. Yogyakarta: CV Andi Offset.

[3] Nazir, Moh. 2011. Metode Penelitian. Bogor: Penerbit Ghalia Indonesia.

[4] Sugiono. 2013. Petunjuk Praktis Penerapan Sistem Jaminan Keamanan Pangan Berbasis HACCP di Rumah Makan dan Restoran. Jakarta: LIPI Press.

[5] Sugiyono. 2009. Metode Penelitian Kuantitatif, Kualitatif dan $R \& D$. Bandung:Alfabeta.

[6] Sulastiyono, Agus. 2011. Manajemen Penyelenggaraan Hotel. Bandung: Alfabeta.

[7] Undang-Undang Republik Indonesia Nomor 10.Tahun 2009 Tentang Kepariwisataan.

[8] Widyastuti, Indah. 2012. Upaya Cheff Untuk Meningkatkan Efisiensi Waktu Pelayanan Kepada Konsumen Di Warung Makan Khas Thailand "Phuket" Yogyakarta. Yogyakarta: AKPAR BSI (Tugas Akhir).

[9] Yuda, Eddy'nya. 2009. Penyajian Makanan (Prinsip Food Hygiene). https://www.scribd.com/doc/183729814/Pe nyajian-Makanan. 5 Januari 2018 